\title{
Isolated arteritis of the epididymis
}

\author{
C WOMACK, ID ANSELL \\ From the Departments of Histopathology, University and City Hospitals, Nottingham
}

SUMMARY The clinical, histological, and immunohistochemical features of two cases of apparently isolated arteritis of the epididymis are presented. The aetiology and pathogenesis of the condition are discussed. Immunoglobulin and complement were shown in the acute arterial lesions, but this is not conclusive evidence that isolated arteritis is either an immune complex disease or a forme fruste of polyarteritis nodosa.

Necrotising arteritis apparently confined to one organ yet showing histological features similar to those seen in polyarteritis nodosa is now well recognised. Since the first description of isolated arteritis in the appendix by Plaut ${ }^{1}$ similar apparently isolated arteritis has been recorded in the gall bladder, ${ }^{2}$ uterine cervix, ${ }^{34}$ uterine body, ${ }^{5}$ skin, ${ }^{6}$ and breast. ${ }^{7}$ The British testicular tumour panel material ${ }^{8}$ included three cases of necrotising arteritis; in one patient the disease was present only in the testis, but his subsequent clinical history is unknown. We report two cases of apparently isolated arteritis of the epididymis in patients who have no clinical evidence of systemic disease.

\section{Case reports}

\section{CASE 1}

A 37 year old man presented with a tender mass in the left testicle which had appeared suddenly three weeks previously. There was no history of recent trauma. An injury to the same testicle some 20 years before had preceded a similar tender mass, which had disappeared spontaneously. There were no other urogenital symptoms and the patient was otherwise fit and well. On examination there was a hard, irregular, tender nodule at the lower pole of the left epididymis; the right testicle was clinically normal. The patient underwent a left orchidectomy via an inguinal incision. He made an uneventful postoperative recovery and is in good physical health two and a half years later. The resected testis measured $6.5 \times 3.5 \times 3.0 \mathrm{~cm}$ and showed no macroscopic abnormality. The lower pole of the epididymis contained a well defined, hard white mass $2 \mathrm{~cm}$ in diameter.

Accepted for publication 14 March 1985
CASE 2

A 14 year old boy was noted to have an undescended right testicle at a routine school medical examination. There was no history of trauma, there were no urogenital symptoms, and the patient was otherwise fit and well. On examination the right testicle was in the inguinal canal and was small and non-mobile. The left testicle was clinically normal. The patient underwent a right orchidectomy because the cord was insufficient to perform orchidopexy. He made an uneventful postoperative recovery and is in good physical health six months later. The resected testis measured $3.5 \times 2.0 \times 2.0$ $\mathrm{cm}$. The testis, epididymis, and cord appeared normal macroscopically.

Both patients were normotensive and neither was taking any drugs before presentation.

\section{INVESTIGATIONS}

Table 1 shows the results of relevant postoperative haematological and biochemical investigations. All were within the normal ranges of the laboratory. Blood eosinophil counts were not performed.

\section{HISTOLOGY}

Routine paraffin embedded tissue sections roughly $7 \mu \mathrm{m}$ thick were stained by haematoxylin and eosin, Martius scarlet blue, and elastic Van Gieson. In case 1 the testis showed no appreciable histological abnormality; in case 2 there was complete absence of germ cells consistent with maldescent. There was a multifocal necrotising arteritis affecting the medium and small muscular arteries of the epididymis in both cases and of the spermatic cord in case 2 . The acute arteritic lesions were characterised by focal fibrinoid necrosis of the vessel wall with an associated infiltrate of neutrophil polymorphonuclear leucocytes and lymphocytes (Fig. 1). Eosinophil polymorphonuclear leucocytes were not 
Table 1 Haematological and biochemical results

\begin{tabular}{|c|c|c|c|c|c|}
\hline \multirow[t]{2}{*}{ Case } & \multicolumn{3}{|l|}{ Blood } & \multicolumn{2}{|l|}{ Serum } \\
\hline & $\begin{array}{l}\text { Erythrocyte sedimentation } \\
\text { rate ( } \mathrm{mm} \text { in the first hour) }\end{array}$ & $\begin{array}{l}\text { Haemoglobin } \\
\text { concentration }(g / d l)\end{array}$ & $\begin{array}{l}\text { White cell count } \\
\left(\times 10^{\circ / l}\right)\end{array}$ & $\begin{array}{l}\text { Urea concentration } \\
\text { (mmol/l) }\end{array}$ & $\begin{array}{l}\text { Creatinine concentration } \\
(\mu \mathrm{mol} / \mathrm{l})\end{array}$ \\
\hline $\begin{array}{l}1 \\
2\end{array}$ & $\begin{array}{l}7 \\
1\end{array}$ & $\begin{array}{l}13.8 \\
15.0\end{array}$ & $\begin{array}{l}5 \cdot 7 \\
5 \cdot 6\end{array}$ & $\begin{array}{l}4 \cdot 3 \\
4 \cdot 5\end{array}$ & $\begin{array}{l}82 \\
87\end{array}$ \\
\hline
\end{tabular}

Values are all within the laboratory normal ranges.

seen and the fibrinoid material stained red with Martius scarlet blue. In some arteries the acute lesions were circumferential. Some arterial lesions were characterised by pronounced intimal (fibrous) thickening and an infiltrate of lymphocytes in the muscular wall without fibrinoid necrosis (Fig. 2). Around all the abnormal arteries there was a lymphocytic infiltrate of variable intensity, which was most striking around the lesions showing fibrinoid necrosis.

\section{IMMUNOHISTOCHEMISTRY}

Paraffin sections were stained for IgG, IgM, IgD, IgA, hepatitis $\mathrm{B}$, and complement components $\mathrm{C} 1 \mathrm{q}$ and $\mathrm{C} 3$ using a standard peroxidase-antiperoxidase technique. Antisera was supplied by Dako UK Ltd. Positive staining was only seen in acute arteritic lesions (Table 2).

\section{Discussion}

The diagnosis of isolated arteritis depends on the clinical exclusion of systemic disease in a patient who has histological evidence of a necrotising arteritis apparently limited to one organ. The histological picture is similar to that seen in classic polyarteritis nodosa, although there are some minor differences in cases of isolated arteritis, notably the lack of thrombosis, aneurysm formation, or infarction. ${ }^{3}$ In some reports the lesions are described as granulomatous, ${ }^{7910}$ but the presence of multinucleated giant cells close to disrupted fragments of arterial elastic lamina (a feature not specific to temporal arteritis) may occur secondarily to vessel wall damage. ${ }^{11}$

To our knowledge isolated arteritis of the

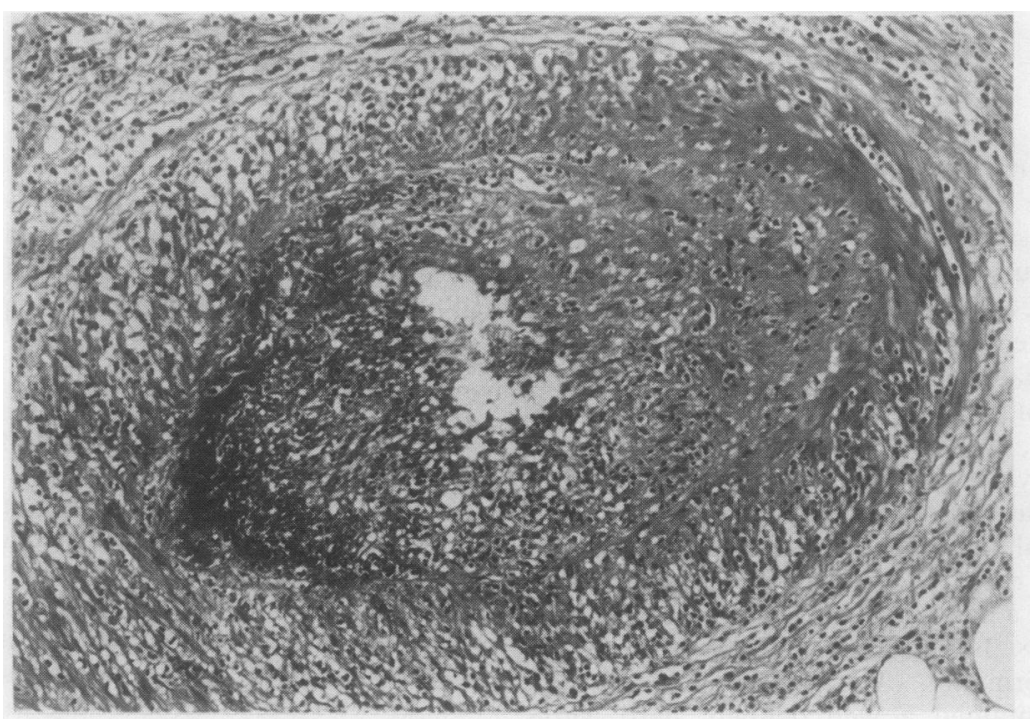

Fig. 1 An acute arteritic lesion. Necrosis and fibrinoid change affects part of the circumference of this artery. There is a moderate inflammatory cell infiltrate around the necrotic area and in a perivascular distribution (from case 1). Haematoxylin and eosin. Original magnification $\times 135$. 


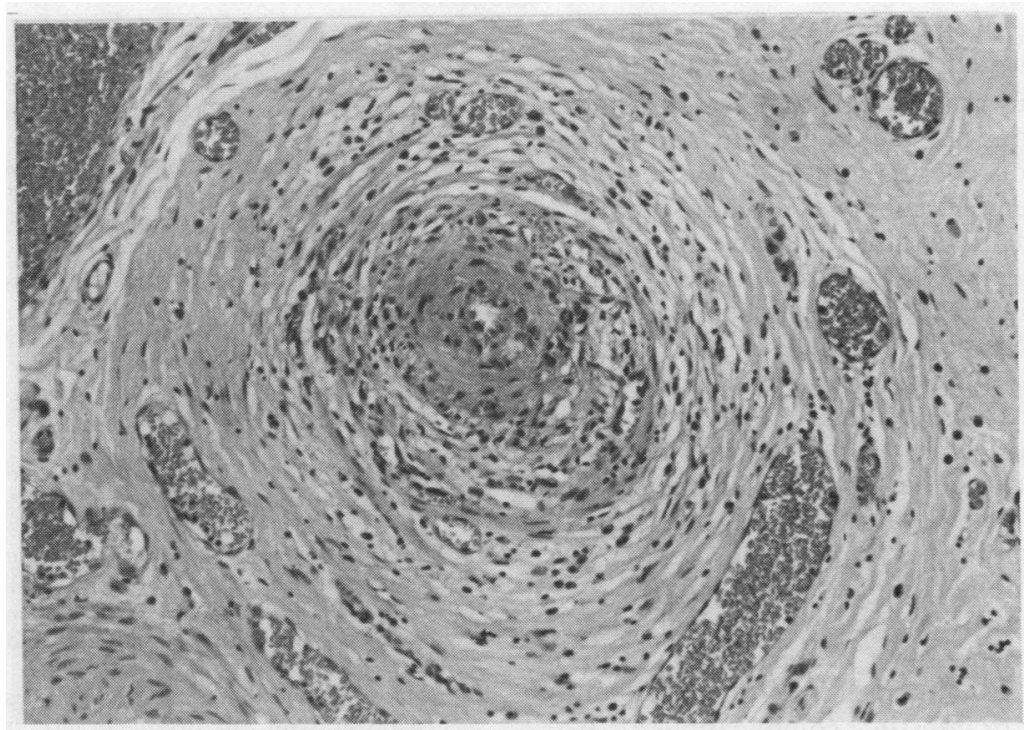

Fig. 2 An older arterial lesion. There is intimal fibrous thickening and a moderate infiltrate of infammatory cells in the muscular wall (from case 2). Haematoxylin and eosin. Original magnification $\times 135$.

epididymis has not been previously reported. Both of our patients had evidence of necrotising arteritis of the epididymis without clinical evidence of systemic disease. The British testicular tumour panel ${ }^{8}$ include three cases of necrotising arteritis: one patient later developed renal lesions and another had rheumatoid arthritis. The third patient in the panel series had a giant cell arteritis of the testis, but his subsequent history is unknown.

The aetiology of isolated arteritis is unknown. Necrotising arteritis is well recognised as a complication of irradiation, but in our cases and in other reports of isolated arteritis there was no history of previous irradiation. Many forms of arteritis are considered to be mediated by immunological mechanisms. Isolated arteritis may represent a localised type III hypersensitivity (Arthus) reaction." Such hypersensitivity to an inhaled antigen has been suggested as one of the causes of the necrotising vasculitis, Wegener's granulomatosis, although no antigen has yet been identified." Sites such as skin, appendix, cervix, uterus, and gall bladder are regularly exposed to a wide variety of antigenic material and an Arthus type reaction can reasonably be proposed as a cause for isolated arteritis at these sites. Similarly, the breasts may be exposed to new antigens during pregnancy and lactation, although the recorded cases of isolated arteritis in this organ have occurred in middle aged and elderly women.?

Potentially antigenic material may be localised in the epididymis following trauma or retrograde flow of urine down the vas deferens. ${ }^{8}$ In our two cases there was no history of recent trauma that could explain the acute arterial lesions. Neither patient complained of urinary symptoms, but we do not know whether there was retrograde flow of urine down the vasa, the likely mechanism of localisation of antigen to the epididymis if a type III hypersensitivity reaction is entailed in the pathogenesis of the arterial lesions. The immunohistochemical staining of our two cases is not, however, conclusive evidence of an immune complex mediated disease. The presence of immunoglobulin and complement in acute arteritic lesions may be due simply to

Table 2 Immunohistological staining of acute arteritic lesions

\begin{tabular}{llllllll}
\hline Case & IgG & IgM & IgA & IgD & Clq & C3 & Hepatitis B \\
\hline 1 & + & + & - & - & - & + & - \\
2 & - & + & - & - & - & - \\
\hline
\end{tabular}

$+=$ staining in acute arteritic lesions.

$-=$ no staining in acute arteritic lesions. 
passive diffusion of plasma constituents through arterial walls damaged by another mechanism.

We have already noted the histological similarities between the lesions of isolated arteritis and polyarteritis nodosa. Polyarteritis nodosa is considered to be an immune complex mediated disease, and $30 \%$ of patients with the disorder have circulating hepatitis B antigen. ${ }^{2}$ We were unable to show hepatitis $B$ antigen immunohistochemically. The positive immunohistochemical staining for IgM and C3 which we have shown in our cases of isolated arteritis is similar to the findings of other workers in the acute arterial lesions of polyarteritis nodosa. ${ }^{12}$ This similarity may not have much significance since we have already noted that the finding of immunoglobulin and complement in arteritic lesions does not prove an immune complex pathogenesis.

Clinically, the two diseases are strikingly different. Polyarteritis nodosa, if untreated, has a poor prognosis; death, usually resulting from renal failure or cardiovascular or intestinal complications. ${ }^{613}$ Isolated arteritis is often asymptomatic and has an excellent prognosis.

It is important that any patient with histological evidence of necrotising arteritis should have full clinical, haematological, and biochemical investigations to exclude systemic disease because of the clinical differences between polyarteritis nodosa and isolated arteritis.

We thank Mr AN Fawcett and Mr CP Bates for permission to publish clinical details of their patients, Mr W Brackenbury for photographic assistance, and Miss Flora Ottawa for typing the original draft.

\section{References}

' Plaut A. Focal arteriolitis. Am J Pathol 1932;8:620-1.

${ }^{2}$ Bohrod MG, Bodon GR. Isolated polyarteritis of the gall bladder. Am Surg 1970;36:681-5.

${ }^{3}$ Ansell ID, Evans DJ, Wright DGD. Asymptomatic arteritis of the uterine cervix. $J$ Clin Pathol 1974;27:664-8.

4 Crow J, McWhinney N. Isolated arteritis of the cervix uteri. Br J Obstet Gynaecol 1979;86:393-8.

' Lin CS, Brazza F. Focal arteritis of uterus. A case report. Mt Sinai J Med 1978;45:402-3.

- Cupps TR, Fauci AS. The vasculitides. In: Cupps TR, Fauci AS eds. Major problems in internal medicine, vol XXI. Philadelphia: WB Saunders, 1981.

' Chiatin B, Kohout ND, Goldman RL. Focal arteritis of the breast. Angiology 1981;32:334-7.

"Morgan AD. Inflammation and infestation of the testis and paratesticular structures. In: Pugh RCB, ed. Pathology of the testis. Oxford: Blackwell Scientific, 1976:119.

" Pirozynski WJ. Giant-cell arteritis of the uterus. Report of two cases. Am J Clin Pathol 1976;65:308-13.

${ }^{10}$ Lasser A, Ghofrany S. Necrotising granulomatous vasculitis (allergic granulomatosis) of the gall bladder. Gastroenterology 1976;71:660-2.

"Mitchinson MJ. The vasculitis syndromes. In: Anthony PP, MacSween RNM, eds. Recent advances in histopathology, vol 12. Edinburgh: Churchill Livingstone, 1984:223-40.

${ }^{12}$ Heptinstall RH. Polyarteritis (periarteritis) nodosa, other forms of vasculitis and rheumatoid arthritis. In: Heptinstall $\mathrm{RH}$ ed. Pathology of the kidney, vol II. 3rd ed. Boston: Little, Brown and Co, 1983: 793-838.

${ }^{13}$ Fauci AS. Vasculitis. J Allergy Clin Immunol 1983;72:211-23.

Requests for reprints to: Dr C Womack, Department of Histopathology, University Hospital, Nottingham NG7 2UH, England. 